\title{
APLICAÇÃO FOLIAR DE MOLIBDÊNIO, PRODUTIVIDADE E QUALIDADE FISIOLÓGICA DE SEMENTES DE FEIJOEIRO IRRIGADO $\left({ }^{1}\right)$
}

ALEXANDRE ARAÚJO ASCOLI $\left({ }^{2}\right)$; ROGÉRIO PERES SORATTO $\left({ }^{3, *}\right)$; WILSON ITAMAR MARUYAMA $\left({ }^{2}\right)$

\section{RESUMO}

O objetivo deste trabalho foi avaliar o efeito de doses e épocas de aplicação de molibdênio, por via foliar, na produtividade e qualidade fisiológica de sementes do feijoeiro 'Pérola' irrigado, cultivado em Neossolo Quatizarênico. Os tratamentos foram constituídos pela aplicação de quatro doses de Mo (0, 40, 80 e $160 \mathrm{~g} \mathrm{ha}^{-1}$ ), aplicadas em duas épocas: 15 ou 26 dias após a emergência das plântulas (DAE). A aplicação de Mo via foliar aumentou a produtividade de sementes e a matéria seca da parte aérea de plântulas do feijoeiro irrigado, cultivado em solo arenoso, independentemente da época de aplicação (15 ou 26 DAE). A germinação das sementes do feijoeiro foi aumentada pela aplicação de Mo aos 26 DAE. Na avaliação do vigor das sementes de feijão, pelo teste de primeira contagem, constatou-se efeito negativo da aplicação de Mo via foliar. A aplicação foliar de Mo aumentou a produtividade do feijoeiro e promoveu a obtenção de sementes que originaram plântulas com maior desenvolvimento inicial.

Palavras-chave: Phaseolus vulgaris, micronutriente, componentes da produção, irrigação, Cerrado.

\section{MOLYBDENUM LEAF APPLICATION, YIELD AND PHYSIOLOGIC QUALITY OF IRRIGATED COMMON BEAN SEEDS}

\begin{abstract}
The objective of this work was to evaluate the effect of doses and time of Mo leaf application on yield and physiologic quality of seeds on irrigated common bean, cultivar Pérola, grown in Typic Quartzipsamment. A randomized complete block design was used, in a factorial array $4 \times 2$ with four replications. The treatments were constituted by four doses of Mo $\left(0,40,80\right.$, and $\left.160 \mathrm{~g} \mathrm{ha}^{-1}\right)$ and two application times: 15 or 26 day after emergence of seedlings. Molybdenum leaf application increased the seed yield and the shoot matter dry of seedlings of irrigated common bean, independently of the application time (15 or $26 \mathrm{DAE}$ ). Common bean seeds germination was increase by Mo leaf application at 26 day after emergence. Common bean seeds vigor, evaluated by first germination count, decreased with Mo leaf application. Molybdenum leaf application increased the common bean seeds yield and promoted of seeds that will originate seedlings with larger initial development.
\end{abstract}

Key words: Phaseolus vulgaris, micronutrient, yield components, irrigation, Cerrado.

( $\left.{ }^{1}\right)$ Recebido para publicação em 15 de maio de 2007 e aceito em 23 de novembro de 2007.

$\left({ }^{2}\right)$ Universidade Estadual de Mato Grosso do Sul (UEMS), Unidade Universitária de Cassilândia, Rod. MS 306, km 06, 79540-000 Cassilândia (MS). E-mail: aaascoli@yahoo.com.br, wilsonmaruyama@yahoo.com.br.

$\left({ }^{3}\right)$ Departamento de Produção Vegetal, Universidade Estadual Paulista (UNESP), Faculdade de Ciências Agronômicas, Fazenda Experimental Lageado, Caixa Postal 237, 18603-970 Botucatu (SP). E-mail: soratto@fca.unesp.br (*) Autor correspondente. 


\section{INTRODUÇÃO}

A possibilidade de cultivar o feijão (Phaseolus vulgaris L.) em uma terceira época (outono-inverno), em regiões de inverno ameno, despertou o interesse de grandes agricultores, que adotam tecnologias avançadas, como o uso de irrigação por pivô central (Borém e Carneiro, 2006). Além da maior produtividade, no cultivo de inverno, é possível colocar feijão no mercado na entressafra, sendo época interessante também para a produção de sementes, devido à menor incidência de pragas, doenças e plantas daninhas, o que torna a cultura uma das mais rentáveis para o cultivo no período de inverno. Porém, apesar da alta tecnologia adotada pelos produtores no cultivo do feijoeiro irrigado, a nutrição mineral muitas vezes vem sendo negligenciada, principalmente em relação aos micronutrientes (TEIXEIRA et al., 2004).

No caso do molibdênio (Mo), devido à deficiência natural de alguns solos, à exportação pelas sementes mediante elevadas produções e à não realização de adubação molíbdica pela maioria dos agricultores, aos poucos estão se exaurindo as reservas naturais do solo, o que pode afetar a capacidade produtiva das culturas (FERREIRA et al., 2003).

O Mo tem importantes funções no sistema enzimático do metabolismo do nitrogênio $(\mathrm{N})$, e, por esse motivo, plantas dependentes de simbiose, quando sujeitas à deficiência desse nutriente, ficam carentes de N (MARschner, 1995; Vieira et al., 1998; Pessoa et al., 2000). No caso do feijoeiro, cujo sistema de fixação de $\mathrm{N}$ é de baixa eficiência, a necessidade do nutriente está mais relacionada à atividade da redutase do nitrato, enzima indispensável no aproveitamento dos nitratos absorvidos pela planta, pois é responsável pela redução do nitrato a nitrito, no processo de assimilação do N (PESSOA et al., 2000; VIEIRA, 2006). Dessa forma, a aplicação de doses elevadas de N, pode não resultar em altas produções, provavelmente devido ao possível acúmulo de nitrato na planta, resultado da nitrificação do amônio e síntese insuficiente de redutase do nitrato, por falta de Mo (MArschner, 1995; Pessoa et al., 2000). Além disso, a aplicação foliar de Mo aumenta a redução do acetileno e a remobilização do $\mathrm{N}$ durante o estádio de enchimento de vagens, e os efeitos combinados desses processos resultam em maior produtividade de grãos (Vieira et al., 1998, Jesus Júnior et al., 2004).

Em diversos trabalhos, constata-se elevação na produção de grãos de feijão com o fornecimento de Mo, seja em aplicação no solo, seja nas sementes (VIEIRA et al., 1992; FulLin et al. 1999), como também em aplicação via foliar (PESSOA et al., 2000; JESUs JÚNIOR et al., 2004).
Conforme a literatura, a dose de Mo via foliar que proporciona a maior produtividade de feijão está entre 80 e $90 \mathrm{~g} \mathrm{ha}^{-1}$ (Berger et al., 1996; PessoA et al., 2000) e, segundo BERGER et al. (1996), a melhor época de aplicação situa-se entre 14 e 28 dias após emergência (DAE). Contudo, os referidos trabalhos foram realizados em solos com altos teores de argila e, segundo Oliveira et al. (1996), em solos ácidos e arenosos há maior deficiência de Mo, o que pode levar à necessidade de maiores doses do nutriente.

O fornecimento adequado e equilibrado de nutrientes para o feijoeiro pode contribuir não só para aumentar a produtividade, mas também para melhorar a qualidade fisiológica das sementes produzidas e desenvolvimento inicial do feijoeiro (PessoA et al., 2000; Teixeira et al., 2005), já que a disponibilidade de nutrientes influencia a formação do embrião e dos cotilédones, com efeitos sobre o vigor das sementes (Teixeira et al., 2005). Porém, no caso do Mo, apesar de sua importância, ainda não foi determinado em que parte constituinte da semente ele se encontra. Sabese apenas que do total de Mo absorvido pelas plantas de feijão, $24 \%$ a $65 \%$ é translocado para as sementes e que a adubação foliar aumenta a concentração de Mo nas sementes (Jасов Neto e Rosseto, 1998; Pessoa et al., 2000).

Vieira (2006) cita melhora na qualidade fisiológica das sementes mediante adubação molíbdica. Contudo, os dados existentes na literatura são escassos e controvertidos. CARVALHo et al. (1998) verificaram efeito positivo da aplicação de Mo via semente ou foliar na qualidade fisiológica de sementes de feijão. Por outro lado, no mesmo tipo de solo, Soratto et al. (2000) e BASSAn et al. (2001) não obtiveram alteração da qualidade de sementes de feijão mediante a aplicação de Mo tanto no sulco quanto foliar.

O objetivo deste trabalho foi avaliar o efeito de doses e épocas de aplicação de Mo, por via foliar, na produtividade e qualidade fisiológica de sementes do feijoeiro comum em cultivo irrigado no inverno, em solo arenoso de Cerrado.

\section{MATERIAL E MÉTODOS}

O trabalho foi realizado sob pivô-central, na Fazenda Cambuí, Município de Cassilândia, MS $\left(52^{\circ} 37^{\prime} \mathrm{W}, 18^{\circ} 47^{\prime} \mathrm{S}\right.$ e $600 \mathrm{~m}$ de altitude), em área utilizada há vários anos com pastagem de Brachiaria brizantha (Hochst ex A.Rich.) Stapf. e cultivada com a sucessão de feijão e pastagem de Panicum maximum Jacq., no ano agrícola 2003/2004. O solo do local é Neossolo Quartzarênico, originalmente sob vegetação de cerrado, cujos resultados de análises química e 
granulométrica, de amostras da camada de $0-20 \mathrm{~cm}$ de profundidade, coletadas 2 meses antes da implantação da cultura do feijão, foram: $\mathrm{pH}\left(\mathrm{CaCl}_{2}\right)$ 5,2; $25 \mathrm{mg} \mathrm{dm}^{-3}$ de $\mathrm{P}$ (resina); $1,1 \mathrm{mmol}_{\mathrm{c}} \mathrm{dm}^{-3}$ de K trocável; $15 \mathrm{mmol}_{\mathrm{c}} \mathrm{dm}^{-3}$ de Ca trocável; $7 \mathrm{mmol}_{\mathrm{c}} \mathrm{dm}^{-3}$ de $\mathrm{Mg}$ trocável; $18 \mathrm{mmol}_{\mathrm{c}} \mathrm{dm}^{-3} \mathrm{de} \mathrm{H}+\mathrm{Al}$; saturação por bases (V\%), $56 \% ; 5 \mathrm{mg} \mathrm{dm}^{-3}$ de S; $0,3 \mathrm{mg} \mathrm{dm}^{-3}$ de B; $0,6 \mathrm{mg} \mathrm{dm}^{-3} \mathrm{de} \mathrm{Cu} ; 10 \mathrm{mg} \mathrm{dm}^{-3}$ de Fe; $10 \mathrm{mg} \mathrm{dm}^{-3} \mathrm{de}$ $\mathrm{Mn} ; 1,2 \mathrm{mg} \mathrm{dm}^{-3}$ de $\mathrm{Zn} ; 28 \mathrm{~g} \mathrm{~kg}^{-1}$ de matéria orgânica; $835 \mathrm{~g} \mathrm{~kg}^{-1}$ de areia; $81 \mathrm{~g} \mathrm{~kg}^{-1}$ de silte; e $84 \mathrm{~g} \mathrm{~kg}^{-1}$ de argila. $\mathrm{O}$ boro e os demais micronutrientes foram extraídos por $\mathrm{BaCl}_{2}$ e DTPA respectivamente. Não foi realizada calagem entre a coleta das amostras e a semeadura do feijão. A área havia recebido calagem um ano antes, ou seja, antes da implantação da cultura de feijão, no ano agrícola 2003/2004.

O solo foi preparado com gradagem pesada e duas gradagens leves, sendo a primeira realizada cerca de quinze dias antes da semeadura e a segunda às vésperas da semeadura.

A adubação de semeadura constou da aplicação, em todos os tratamentos, de $24 \mathrm{~kg}$ de $\mathrm{N} \mathrm{ha}^{-}$ $1,88 \mathrm{~kg}$ de $\mathrm{P}_{2} \mathrm{O}_{5} \mathrm{ha}^{-1} ; 48 \mathrm{~kg}$ de $\mathrm{K}_{2} \mathrm{O} \mathrm{ha}^{-1}$ e $25 \mathrm{~kg}$ de $\mathrm{S}$ $\mathrm{ha}^{-1}$, utilizando a fórmula $06-22-12+6,25 \%$ de S. A semeadura do feijoeiro, cultivar Pérola, foi realizada mecanicamente em 5/6/2005, no espaçamento de 0,45 $m$ entrelinhas e sementes necessárias para se obter 1517 plantas por metro. As sementes foram tratadas com carboxim + thiram $(200+200 \mathrm{~g}$ do i.a. por $100 \mathrm{~kg}$ de sementes). A emergência das plantas ocorreu em 11/ $6 / 2005$.

O delineamento experimental utilizado foi o de blocos ao acaso, no esquema fatorial $4 \times 2$, com quatro repetições. Os tratamentos foram constituídos pela aplicação de quatro doses de $\operatorname{Mo}(0,40,80$ e 160 $\mathrm{g} \mathrm{ha}^{-1}$ ) e duas épocas de aplicação (15 ou 26 DAE), tendo como fonte o molibdato de amônio ( $54 \%$ de Mo), com auxílio de pulverizador costal com capacidade para $20 \mathrm{~L}$, utilizando vazão de $200 \mathrm{~L} \mathrm{ha}^{-1}$. As pulverizações para o fornecimento de Mo foram realizadas sempre entre 5 e 6 horas da tarde, horário de menor ocorrência de ventos. Cada parcela foi constituída por cinco linhas de 6,0 m de comprimento. A área útil foi constituída pelas três linhas centrais, desprezando-se $0,50 \mathrm{~m}$ em ambas as extremidades de cada linha.

As adubações de cobertura foram realizadas via pivô central, com a aplicação de $35 \mathrm{~kg}^{\mathrm{de}} \mathrm{N} \mathrm{ha}^{-1}$, $21 \mathrm{~kg}$ de $\mathrm{K}_{2} \mathrm{O}$ ha $^{-1}$ e $11,9 \mathrm{~kg}$ de S ha- ${ }^{-1}$, aos $20 \mathrm{DAE}$, utilizando o adubo formulado $25-00-15+8,5 \%$ de $\mathrm{S}$ e $38,4 \mathrm{~kg}$ de $\mathrm{N} \mathrm{ha}^{-1}, 76,8 \mathrm{~kg}$ de $\mathrm{K}_{2} \mathrm{O} \mathrm{ha}^{-1}$ e $12 \mathrm{~kg}$ de $\mathrm{S}$ $\mathrm{ha}^{-1}$, aos $30 \mathrm{DAE}$, utilizando o adubo formulado 16$00-32+5,0 \%$ de $S$.
O controle de plantas daninhas foi realizado utilizando-se os herbicidas seletivos bentazon $(720 \mathrm{~g}$ do i.a. ha- $\left.{ }^{-1}\right)$ e fluazifop-p-butil (200 g do i.a. ha $\left.{ }^{-1}\right)$, recomendados para a cultura do feijoeiro.

A irrigação foi realizada durante todo o ciclo da cultura por meio de aspersão com um pivô central dotado de difusores. O manejo da irrigação foi realizado por meio de balanço hídrico, sendo utilizada uma estação meteorológica automatizada para fornecimento das informações de evapotranspiração diária e precipitação pluvial, necessárias para o cálculo do balanço.

Durante o desenvolvimento da cultura, foram realizados os demais tratos culturais e fitossanitários recomendados.

$\mathrm{Na}$ área útil de cada parcela, foram avaliados os componentes da produção: número de vagens por planta, número médio de sementes por vagem, massa de cem sementes e produção de sementes, foi feita a pesagem das sementes obtidas na área útil de cada parcela e os dados foram transformados em kg ha ${ }^{-1}$ (13\% base úmida).

Seis meses após a colheita, as sementes foram avaliadas quanto: à germinação; à primeira contagem de germinação; à de emergência em campo; ao índice de velocidade de emergência; à condutividade elétrica; e à massa seca da parte aérea das plântulas. A germinação foi realizada com uma subamostra de 50 sementes de cada parcela.

As sementes foram colocadas eqüidistantemente em rolos de papel "germitest" umedecido com água deionizada, em quantidade equivalente a 2,5 vezes a sua massa, e mantidas em germinador à temperatura de 25 ${ }^{\circ} \mathrm{C}$. As contagens foram realizadas aos 5 e 9 dias após a montagem do teste, para se indicar a porcentagem de plântulas normais (BRASIL, 1992). A primeira contagem de germinação foi realizada em conjunto com o teste de germinação, tendo-se computado as porcentagens de plântulas normais verificadas no quinto dia após a montagem.

No teste de emergência em campo foram semeadas 50 sementes de cada parcela, distribuídas em sulcos de $2 \mathrm{~m}$ de comprimento e $2 \mathrm{~cm}$ de profundidade, tendo-se mantido as sementes eqüidistantes, $4 \mathrm{~cm}$ uma da outra.

Os sulcos foram espaçados de $20 \mathrm{~cm}$, e as contagens foram realizadas aos 21 dias após a semeadura, tendo-se computado as plântulas com os cotilédones acima da superfície do solo e com as folhas simples com as margens sem se tocar. 
O índice de velocidade de emergência (IVE) foi determinado em conjunto com o teste de emergência de plântulas em campo, tendo-se anotado, diariamente, no mesmo horário, o número de plântulas cujas folhas embrionárias estavam visíveis. No fim do teste, com os dados diários do número de plântulas normais, calculou-se o IVE com a fórmula proposta por MAGUIRE (1962).

Para a determinação da condutividade elétrica, utilizou-se uma subamostra de 50 sementes de cada parcela, pesadas e colocadas em um recipiente com $75 \mathrm{~mL}$ de água destilada e mantidas durante 24 horas em germinador a $25^{\circ} \mathrm{C}$. Após esse período, foi feita a leitura dos exsudatos liberados na água, com o auxílio do condutivímetro, modelo Marconi CA-150, e o valor foi expresso em $\mu \mathrm{cm}^{-1}$ $\mathrm{g}^{-1}$ (Vieira e Krzyzanowski, 1999).

A massa de matéria seca da parte aérea das plântulas foi obtida com o teste instalado para avaliação da emergência de plântulas no campo. Após 21 dias da semeadura, 25 plântulas foram arrancadas, e tiveram a parte aérea separada do sistema radicular. Foram então colocadas em saco de papel e levadas para a estufa com circulação de ar forçado, mantida à temperatura de $65^{\circ} \mathrm{C}$, até massa constante. Foram utilizadas quatro repetições por tratamento.

Os resultados foram submetidos à análise de variância. As médias referentes à época de aplicação de Mo foram comparadas pelo teste $\mathrm{t}$ $(P<0,05)$, enquanto os efeitos das doses foram avaliados pela análise de regressão, adotando-se como critério para escolha do modelo a magnitude dos coeficientes de regressão significativos a 5\% de probabilidade pelo teste F. Foram realizadas análises de correlação simples entre os componentes da produção e a produtividade de sementes do feijoeiro, visando determinar o grau de associação entre as variáveis.

\section{RESULTADOS E DISCUSSÃO}

Os tratamentos não interferiram no ciclo da cultura, o florescimento pleno ocorreu aos 44 DAE e o ciclo teve a duração de 89 dias.

Os componentes da produção (número de vagens por planta, de sementes por vagem e massa de 100 sementes) não foram afetados pelos tratamentos (Tabela 1). Resultados semelhantes foram observados por Soratto et al. (2000) e BASSAN et al. (2001). Porém, ANDRAde et al. (1998) observaram aumento no número de vagens por planta e na massa de 100 grãos, com a aplicação do Mo via foliar no feijoeiro. Para esses autores, o número de sementes por vagem é uma característica de alta herdabilidade genética, com pouca influência do ambiente. É importante ressaltar que houve boa precisão experimental, indicada pelos baixos valores de coeficientes de variação.

Tabela 1. Valores médios de número de vagens por planta, número de sementes por vagem, massa de 100 sementes, produtividade, germinação, vigor (primeira contagem, emergência em campo, índice de velocidade de emergência e condutividade elétrica do exsudado) de sementes e massa de matéria seca de plântulas de feijão em função de épocas de aplicação foliar de Mo

\begin{tabular}{lcrr}
\hline \multirow{2}{*}{ Variável analisada } & \multicolumn{2}{c}{ Época de aplicação (DAE) ${ }^{1}$ ) } & CV (\%) \\
\cline { 2 - 4 } Número de vagens por planta & 15 & 26 & 15,1 \\
Número de sementes por vagem & $11,0 \mathrm{a}$ & $11,1 \mathrm{a}$ & 6,2 \\
Massa de 100 sementes $(\mathrm{g})$ & $4,3 \mathrm{a}$ & $4,3 \mathrm{a}$ & 4,5 \\
Produtividade de sementes $\left(\mathrm{kg} \mathrm{ha}^{-1}\right)$ & $24,0 \mathrm{a}$ & $23,5 \mathrm{a}$ & 6,6 \\
Germinação $\%$ (\%) & $3.567,0 \mathrm{a}$ & $3.420,0 \mathrm{a}$ & 6,0 \\
Primeira contagem $(\%)$ & $93,9 \mathrm{~b}$ & $98,4 \mathrm{a}$ & 10,2 \\
Emergência em campo $(\%)$ & $87,9 \mathrm{a}$ & $90,6 \mathrm{a}$ & 8,4 \\
Índice de velocidade de emergência & $87,5 \mathrm{a}$ & $89,0 \mathrm{a}$ & 10,4 \\
Condutividade elétrica $\left(\mu \mathrm{cm}^{-1} \mathrm{~g}^{-1}\right)$ & $5,5 \mathrm{a}$ & $5,8 \mathrm{a}$ & 8,6 \\
Massa de matéria seca $\left(\mathrm{g} \mathrm{plântula}^{-1}\right)$ & $65,4 \mathrm{a}$ & $67,1 \mathrm{a}$ & 11,4 \\
\hline
\end{tabular}

Médias seguidas de letras distintas na linha diferem entre si pelo teste $\mathrm{t}(P<0,05) .{ }^{(1)} \mathrm{DAE}$ : dias após emergência. 
Apesar de não ter interferido significativamente nos componentes da produção, as doses de Mo aumentaram a produtividade de sementes (Figura 1). Verifica-se que os dados se ajustaram a uma função quadrática. A dose estimada de 101,2 $\mathrm{g} \mathrm{ha}^{-1}$ de Mo proporcionou a maior eficiência técnica, com aumento de $324,7 \mathrm{~kg} \mathrm{ha}^{-1}$, ou seja, 9,8\% em relação à testemunha (sem aplicação de Mo). PESSOA et al. (2000) e JESUS JúNIOR et al, (2004) também obtiveram aumento da produtividade do feijoeiro com a aplicação de Mo via foliar. Altas concentrações de molibdato de amônio (160 $\left.\mathrm{g} \mathrm{ha}^{-1} \mathrm{de} \mathrm{Mo}\right)$ via foliar, podem ter provocado efeito tóxico às plantas. Resultados semelhantes foram obtidos por BERGER et al. (1996) e FERREIRA et al. (2003).
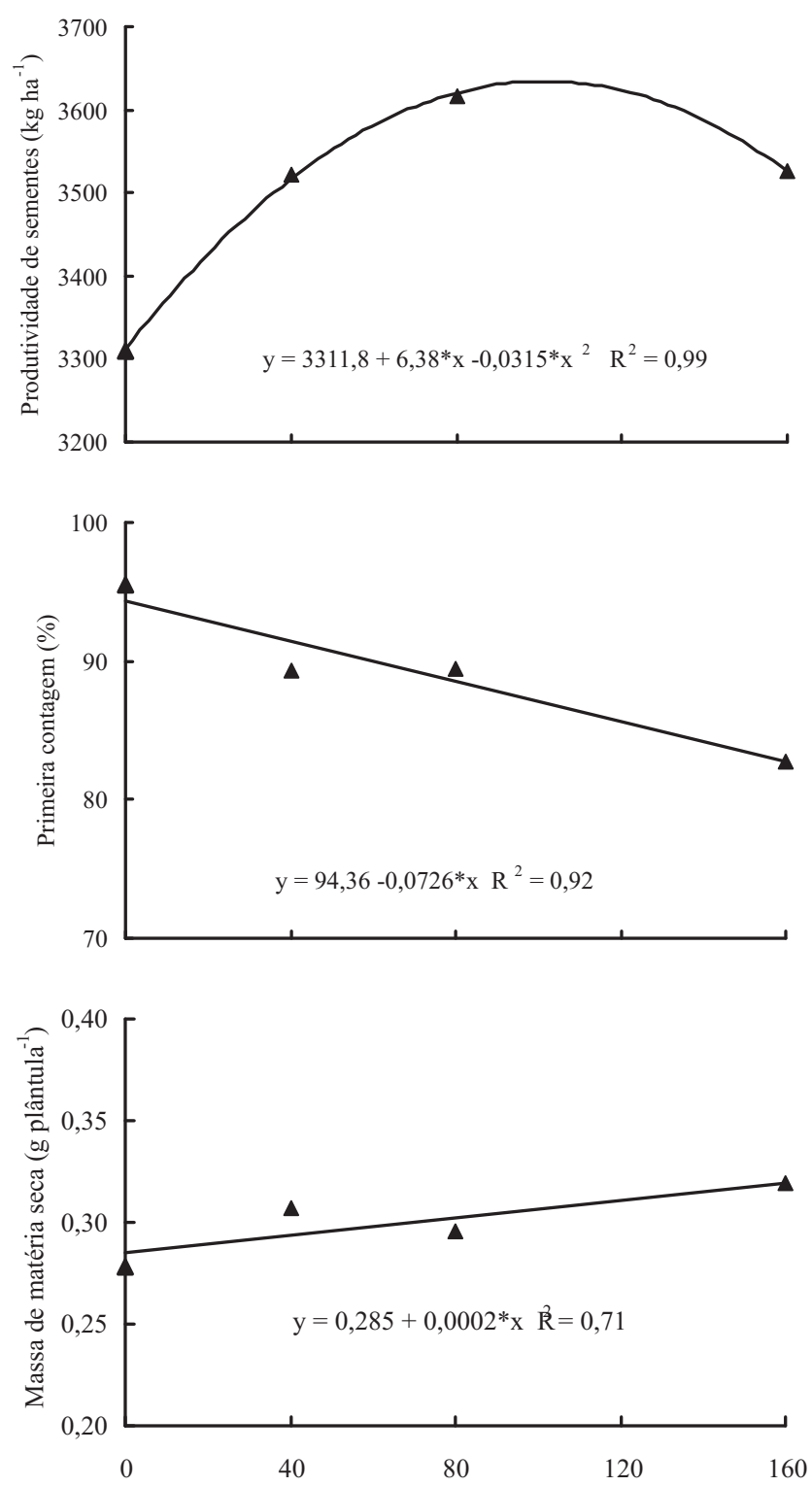

Figura 1. Produtividade de sementes, vigor (primeira contagem) e massa de matéria seca da parte aérea de plântulas de feijão em função de doses de Mo via foliar. Média de duas épocas de aplicação. * é significativo $P<0,05$ pelo teste $\mathrm{t}$.
Segundo VIEIRA et al. (1998), a aplicação de Mo propicia maior atividade das enzimas nitrogenase e redutase do nitrato, responsáveis pela catálise da fixação do $\mathrm{N}_{2}$ atmosférico e da redução do nitrato. Contudo, no presente experimento, como foram fornecidos 97,4 $\mathrm{kg} \mathrm{ha}^{-1}$ de $\mathrm{N}$, parcelados na semeadura, aos 20 e 30 DAE e, considerando que o feijão possui um sistema de fixação de baixa eficiência, o aumento de produtividade provavelmente está relacionado com a atividade da redutase do nitrato, enzima indispensável no aproveitamento do nitrato absorvido pela planta (PESSOA et al., 2000; VIEIRA, 2006). PESSOA et al. (2000) verificaram maiores teores de $\mathrm{N}$ total e $\mathrm{N}$ orgânico nas folhas do feijoeiro em função da aplicação de Mo via foliar, o que indica efeito positivo do micronutriente no aproveitamento do N absorvido pela planta. Ferreira et al. (2003) obtiveram aumento na produtividade do feijoeiro com a aplicação foliar de Mo, independentemente do teor de Mo nas sementes utilizadas na semeadura. FulLIN et al. (1999) verificaram que a aplicação de $\mathrm{N}$ no solo é imprescindível para aumentar o efeito do Mo pulverizado nas folhas. Tais resultados indicam que mesmo quando suprida a necessidade de $\mathrm{N}$, a planta de feijão pode não atingir a produtividade máxima, se o fornecimento de Mo não for suficiente. Para esses autores a aplicação de Mo via foliar foi mais eficiente do que quando aplicado por meio da peletização das sementes.

$\mathrm{O}$ acréscimo na produtividade de sementes neste trabalho não foi expressivo como os $163 \%$ obtidos por BERGER et al. (1996), ou os $200 \%$ constatados por VieIRA et al. (1992). Porém, como o fornecimento de Mo é relativamente barato e pode ser realizado em conjunto com a aplicação de defensivos (Silva et al., 2003), 324,7 kg ha ${ }^{-1}(9,8 \%)$ de acréscimo na produtividade de sementes pode ser viável economicamente, principalmente para produtores que já adotam altos níveis tecnológicos e conseguem elevadas produtividades.

Apesar de não ter apresentado diferenças, a tendência de aumento na massa de 100 sementes proporcionada pela aplicação de Mo, provavelmente contribuiu para maior produtividade, já que somente esse componente da produção se correlacionou significativamente $\left(\mathrm{r}=0,38^{*}\right)$ com a produtividade. Coelho et al. (2001) verificaram aumento de $5 \%$ na massa de 100 sementes e $17 \%$ na produtividade do feijoeiro, com aplicação via foliar de $75 \mathrm{~g} \mathrm{ha}^{-1}$ de Mo. Segundo esses autores o aumento da produtividade está relacionado com o acréscimo no teor de $\mathrm{N}$ orgânico e na massa das sementes, proporcionados pelo Mo. 
A época de aplicação afetou a germinação das sementes, e a aplicação aos 26 DAE proporcionou aumento dessa variável (Tabela 1). BASSAN et al. (2001) verificaram redução na germinação das sementes de feijão obtidas em tratamento com a aplicação foliar de $75 \mathrm{~g} \mathrm{ha}^{-1}$ de Mo aos 23 DAE, em comparação com a testemunha. É importante ressaltar que o valor médio para o teste de germinação foi de $96 \%$, portanto, bem acima do padrão mínimo para comercialização de sementes de feijão no Brasil, atualmente de $80 \%$ (BRASIL, 1992).

O vigor das sementes, avaliado pelos testes de primeira contagem, foi reduzido pelo aumento da dose de Mo via foliar, havendo redução de, aproximadamente, $10 \%$ na germinação na primeira contagem com a aplicação da maior dose, em relação ao tratamento sem o fornecimento de Mo (Figura 1). CARVALHO et al. (1998) não verificaram alteração dessa variável com a aplicação de Mo via foliar no feijoeiro. As divergências nos resultados podem estar relacionadas com o tipo de solo utilizado, com o teor de Mo nas sementes e com a dose de $\mathrm{N}$ aplicada. Segundo KRZYZANOWSKI et al. (1991), o vigor das sementes é de extrema importância, pois sementes com baixo vigor, mesmo com alta porcentagem de germinação, podem resultar em prejuízos aos agricultores, quando submetidas a condições desfavoráveis de campo, principalmente pelo estabelecimento inadequado de estande. Contudo, apesar da redução no vigor com a aplicação de Mo, mesmo nas maiores doses a germinação na primeira contagem indicou sementes com alto vigor, com média superior a $83 \%$.

$\mathrm{Na}$ avaliação do vigor, mediante os testes de emergência em campo e IVE, não foram constatados efeitos dos tratamentos (Tabela 1). Resultados semelhantes foram observados por CARVALHO et al. (1998) e BASSAN et al. (2001).

No teste de condutividade elétrica, constatouse interação significativa entre doses e épocas de aplicação (Tabela 2). Verifica-se que a aplicação de $80 \mathrm{~g} \mathrm{ha}^{-1} \mathrm{de}$ Mo aos 15 DAE proporcionou menor valor de condutividade elétrica do extrato, do que aos 26 DAE. Geralmente valores maiores de condutividade elétrica são ocasionados pela maior liberação de exsudatos no meio, em virtude do comprometimento da integridade das membranas, e estão relacionados a sementes de qualidade inferior (VIEIRA e KRZYZANOVSKI, 1999).

Apesar dos efeitos na germinação e no vigor das sementes não terem sido expressivos, a aplicação de doses crescentes de Mo via foliar proporcionou aumento linear da matéria seca da parte aérea de plântulas, o que pode estar relacionado com um maior teor de Mo nas sementes, provavelmente proporcionado pelas maiores doses de Mo (Figura 1). De acordo com CARVAlHo e NAKAgaWa (2000) e Teixeira et al. (2005), são de extrema importância a capacidade de emergência das sementes no campo e o vigor do desenvolvimento inicial, para se assegurar adequado estabelecimento e estande da cultura, sendo tais características influenciadas pelo estado nutricional da planta. TANNER (1979) constatou que a população de plantas, a massa foliar e a produtividade do milho foram significativamente reduzidas quando o conteúdo de Mo na semente era baixo. Para BRODRICK et al. (1992), em feijoeiros originados de sementes com maior conteúdo de Mo observou-se maior massa dos nódulos, acúmulo de $\mathrm{N}$ com produção de mais sementes.

Tabela 2. Desdobramento da interação significativa entre dose e época de aplicação foliar de Mo no feijoeiro, referente ao vigor (condutividade elétrica do exsudado) das sementes

\begin{tabular}{llr}
\hline \multirow{2}{*}{ Dose de molibdênio } & \multicolumn{2}{c}{ Época de aplicação (DAE) $\left(^{1}\right)$} \\
\cline { 2 - 3 }$\left(\mathrm{g} \mathrm{ha}^{-1}\right)$ & \multicolumn{1}{c}{26} \\
\cline { 2 - 3 } 0 & $65,5 \mathrm{a}$ & $\left.65,5 \mathrm{a} \mathrm{cm}^{-1} \mathrm{~g}^{-1}\right)$ \\
40 & $69,6 \mathrm{a}$ & $64,3 \mathrm{a}$ \\
80 & $60,8 \mathrm{~b}$ & $69,9 \mathrm{a}$ \\
160 & $65,7 \mathrm{a}$ & $68,2 \mathrm{a}$ \\
\hline DMS $(P<0,05) \mathrm{E}(\mathrm{D})$ & \multicolumn{3}{c}{8,4} \\
\hline
\end{tabular}

Médias seguidas de letras distintas na linha diferem entre si pelo teste $\mathrm{t}(P<0,05) .\left({ }^{1}\right)$ DAE: dias após emergência.

Os resultados indicam ser possível aumentar a produtividade do feijoeiro irrigado em solo arenoso com a aplicação foliar de Mo e promover a obtenção de sementes que vão dar origem a plântulas com maior desenvolvimento inicial, sendo assim uma técnica interessante para uso em áreas de produção de sementes de feijão sob irrigação na região do cerrado.

\section{CONCLUSÕES}

1. A aplicação de Mo via foliar aumenta a produtividade de sementes e a matéria seca da parte aérea de plântulas do feijoeiro irrigado, cultivado em solo arenoso, independentemente da época de aplicação (15 ou 26 DAE).

2. A aplicação de Mo aos 26 DAE aumenta a porcentagem de germinação das sementes do feijoeiro.

3. O vigor das sementes de feijão, avaliado pelo teste de primeira contagem, admite efeito linear negativo com a aplicação de Mo via foliar. 


\section{AGRADECIMENTOS}

A Senhora Luciana Carvalho Dias, proprietária da Fazenda Cambuí, por ter cedido a área para o desenvolvimento do trabalho.

\section{REFERÊNCIAS}

ANDRADE, M.J.B.; DINIZ, A.R.; CARVALHO, J.G.; LIMA, S.F. Resposta da cultura do feijoeiro à aplicação foliar de molibdênio e às adubações nitrogenadas de plantio e cobertura. Ciência e Agrotecnologia, Lavras, v.22, n.4, p.499508, 1998.

BASSAN, D.A.Z.; ARF, O.; BUZETTI, S.; CARVALHO, M.A.C.; SANTOS, N.C.B.; SÁ, M.E. Inoculação de sementes e aplicação de nitrogênio e molibdênio na cultura do feijão de inverno: produção e qualidade fisiológica de sementes. Revista Brasileira de Sementes, Brasília, v.23, n.1, p.76-83, 2001.

BERGER, P.G.; VIEIRA, C.; ARAÚJO, G.A.A. Efeitos de doses e épocas de aplicação de molibdênio sobre a cultura do feijão. Pesquisa Agropecuária Brasileira, Brasília, v.31, n.7, p.473-480, 1996.

BORÉM, A.; CARNEIRO, J.E.S. A cultura. In: VIEIRA, C.; PAULA JÚNIOR, T.J.; BORÉM, A. (Eds.). Feijão. 2 ed. Atual. Viçosa: UFV, 2006. p.13-18.

BRASIL. Ministério da Agricultura. Regras para análise de sementes. Brasília: SNAD/DNPV/CLAV, 1992.365p.

BRODRICK, S.J.; SAKALA, M.K.; GILLER, K.E. Molybdenum reserves of seed, and growth and $\mathrm{N}_{2}$ fixation by Phaseolus vulgaris L. Biology and Fertility of Soils, Berlin, v.13, n.1, p.3944, 1992.

CARVALHO, E.G.; ARF, O.; SÁ, M.E.; BUZETTI, S. Efeito de nitrogênio, molibdênio e inoculação das sementes em feijoeiro (Phaseolus vulgaris L.) na região de Selvíria, MS. II - Qualidade fisiológica e desempenho das sementes no campo. Científica, São Paulo, v.26, n.1, p.59-71, 1998.

CARVALHO, N.M.; NAKAGAWA, J. Sementes: ciência, tecnologia e produção. 4 ed. Jaboticabal: FUNEP, 2000. 588p.

COELHO, F.C.; FREITAS, S.P.; MONERAT, P.H.; DORNELLES, M.S. Efeitos sobre a cultura do feijão das adubações com nitrogênio e molibdênio e do manejo da plantas daninhas. Revista Ceres, Viçosa, v.48, p.455-467, 2001.

FERREIRA, A.C.B.; ARAÚJO, G.A.A.; CARDOSO, A.A.; FONTES, P.C.R.; VIEIRA, C. Características agronômicas do feijoeiro em função do molibdênio contido na semente e da sua aplicação via foliar. Acta Scientiarum: Agronomy, Maringá, v.25, n.1, p.65-72, 2003.

FULLIN, E.A.; ZANGRANDE, M.B. LANI, J.A.; MENDONÇA, L.F.; DESSAUNE FILHO, N. Nitrogênio e molibdênio na adubação do feijoeiro irrigado. Pesquisa Agropecuária Brasileira, Brasília, v.34, n.7, p.1145-1149, 1999.
JACOB NETO, J.; ROSSETTO, C.A.V. Concentração de nutrientes nas sementes: o papel do molibdênio. Floresta e Ambiente, Seropédica, v.5, n.1, p.171-183, 1998.

JESUS JÚNIOR, W.C.; VALE, F.X.R.; COELHO, R.R.; HAU, B.; ZAMBOLIM, L.; BERGER, R.D. Management of angular leaf spot in common bean (Phaseolus vulgaris L.) with molybdenum and fungicide. Agronomy Journal, Madison, v.96, n.3, p.665670, 2004.

KRZYZANOWSKI, F.C.; FRANÇA NETO, J.B.; HENNING, A.A. Relatos dos testes de vigor disponíveis para as grandes culturas. Informativo ABRATES, Londrina, v.1, n.1, p.15-50, 1991.

MAGUIRE, J.D. Speed of germination-aid in selection and evaluation for seedling emergence and vigor. Crop Science, Madison, v.2, p.176-177, 1962.

MARSCHNER, H. Mineral nutrition of higher plants. 2.ed. San Diego: Academic Press, 1995. 889p.

OLIVEIRA, I.P.; ARAÚJO, R.S.; DUTRA, L.G. Nutrição mineral e fixação biológica de nitrogênio. In: ARAÚJO, R.S.; RAVA, C.A.; STONE, L.F.;ZIMMERMANN, M.J.O. (Coords.). Cultura do feijoeiro comum no Brasil. Piracicaba: Potafos, 1996. p.169221.

PESSOA, A.C.S.; RIBEIRO, A.C.; CHAGAS, J.M.; CASSINI, S.T.A. Concentração foliar de molibdênio e exportação de nutrientes pelo feijoeiro "Ouro Negro" em resposta à adubação foliar com molibdênio. Revista Brasileira de Ciência do Solo, Viçosa, v.24, n.1, p.75-84, 2000.

SILVA, M.V.; ANDRADE, M.J.B.; RAMALHO, M.A.P.; ALVES, V.G. Aplicação foliar simultânea de molibdênio e alguns defensivos agrícolas na cultura do feijoeiro. Ciência e Agrotecnologia, Lavras, v.27, n.5, p.1160-1164, 2003.

SORATTO, R.P.;SILVA, T.R.B.; CHIDI, S.N.; ARF, O.; SÁ, M.E.; BUZETTI, S. Feijoeiro irrigado e aplicação de nitrogênio em cobertura e molibdênio via foliar. Cultura Agronômica, Ilha Solteira, v.9, n.1, p.115-32, 2000.

TANNER, P.D. The effect of molybdenum on maize seed quality. Rhodesian Journal of Agricultural Research, Harare, v.17, n.1, p.125-129, 1979.

TEIXEIRA, I.R.; BORÉM, A.; ANDRADE, M.J.B.; GIÚDICE, M.P.D.; CECON, P.R. Teores de clorofila em plantas de feijoeiros influenciadas pela adubação com manganês e zinco. Acta Scientiarum: Agronomy, Maringá, v.26, n.1, p.147-152, 2004.

TEIXEIRA, I.R.; BORÉM, A.; ARAÚJO, G.A.A.; ANDRADE, M.J.B. Teores de nutrientes e qualidade fisiológica de sementes de feijão em resposta à adubação foliar com manganês e zinco. Bragantia, Campinas, v.64, n.1, p.83-88, 2005.

VIEIRA, C. Adubação mineral e calagem. In: VIEIRA, C.; PAULA JÚNIOR, T.J.; BORÉM, A. (Eds.). Feijão. 2 ed. Atul. Viçosa: UFV, 2006. p.115-142. 
VIEIRA, C.; NOGUEIRA, A.O.; ARAÚJO, G.A. de A. Adubação nitrogenada e molíbdica na cultura do feijão. Revista de Agricultura, Piracicaba, v.67, n.2, p.117-124, 1992.

VIEIRA, R.D.; KRZYZANOWSKI, F.C. Teste de condutividade elétrica. In: KRZYZANOWSKI, F.C.; VIEIRA, R.D.; FRANÇA NETO, J.B.F. Vigor de sementes: conceitos e testes. Londrina: ABRATES, 1999. p.1-26.
VIEIRA, R.F.; CARDOSO, E.J.B.N.; VIEIRA, C.; CASSINI, S.T.A. Foliar application of molybdenum in common beans. I. Nitrogenase and nitrate reductase activities in a soil of high fertility. Journal of Plant Nutrition, Athens, v.21, n.2, p.169180, 1998. 